\title{
Intracoronary levosimendan during ischemia prevents myocardial apoptosis
}

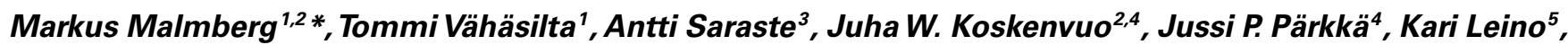 Timo Laitio ${ }^{5}$, Christoffer Stark ${ }^{2}$, Aira Heikkilä ${ }^{6}$, Pekka Saukko ${ }^{7}$ and Timo Savunen ${ }^{1,2}$}

${ }^{1}$ Department of Surgery, Turku University Hospital, Turku, Finland

${ }^{2}$ Research Centre of Applied and Preventive Cardiovascular Medicine, Turku University, Turku, Finland

${ }^{3}$ Department of Medicine, Turku University Hospital, Turku, Finland

${ }^{4}$ Department of Clinical Physiology, Nuclear Medicine and Positron Emission Tomography, Turku University Hospital, Turku, Finland

${ }^{5}$ Department of Anesthesiology, Intensive Care, Emergency Care and Pain Medicine, Turku University Hospital, Turku, Finland

${ }^{6}$ Orion Pharma, Espoo, Finland

${ }^{7}$ Department of Forensic Medicine, Turku University, Turku, Finland

\section{Edited by:}

Junhui Sun, National Institutes of

Health, USA

Reviewed by:

Samarjit Das, Johns Hopkins

University, USA

Nian-Qing (Nan) Shi, University of

Wisconsin-Madison, USA

*Correspondence:

Markus Malmberg, Department of Surgery, Turku University Hospital, Kiinamyllynkatu 4-8, PL 52, 20521 Turku, Finland.

e-mail:markus.malmberg@utu.fi
Background: Levosimendan is a calcium sensitizer that has been shown to prevent myocardial contractile depression in patients post cardiac surgery. This drug exhibits an anti-apoptotic property; however, the underlying mechanism remains elusive. In this report, we characterized the myocardial protective of levosimendan in preventing cardiomyocyte apoptosis and post-operative stunning in an experimental ischemia-reperfusion model. Methods: Three groups of pigs ( $n=8$ per group) were subjected to $40 \mathrm{~min}$ of global, cardioplegic ischemia followed by $240 \mathrm{~min}$ of reperfusion. Levosimendan $(65 \mu \mathrm{g} / \mathrm{kg}$ body weight) was given to pigs by intravenous infusion (L-IV) before ischemia or intracoronary administration during ischemia (L-IC). The Control group did not receive any levosimendan. Echocardiography was used to monitor cardiac function in all groups. Apoptosis levels were assessed from the left ventricle using the terminal transferase mediated dUTP nick end labeling (TUNEL) assay and immunocytochemical detection of Caspase-3. Results: Pigs after ischemia-reperfusion had a much higher TUNEL\%, suggesting that our treatment protocol was effective. Levels of apoptosis were significantly increased in Control pigs that did not receive any levosimendan $(0.062 \pm 0.044 \%)$ relative to those received levosimendan either before $(0.02 \pm 0.017 \%, p=0.03)$ or during $(0.02 \pm 0.017 \%, p=0.03)$ the ischemia phase. Longitudinal left ventricular contraction in pigs that received levosimendan before ischemia $(0.75 \pm 0.12 \mathrm{~mm})$ was significantly higher than those received levosimendan during ischemia $(0.53 \pm 0.11 \mathrm{~mm}, p=0.003)$ or Control pigs $(0.54 \pm 0.11 \mathrm{~mm}, p=0.01)$. Conclusion: Our results suggested that pigs received levosimendan displayed a markedly improved cell survival post I-R. The effect on cardiac contractility was only significant in our perfusion heart model when levosimendan was delivered intravenously before ischemia.

Keywords: myocardial protection, apoptosis, ischemia/reperfusion injury, animal model

\section{INTRODUCTION}

A successful myocardial protection during open heart surgery has an important clinical significance for overall short- and longterm outcome. Ischemia-reperfusion injury and concomitantly induced cardiomyocyte apoptosis (Gottlieb et al., 1994; Wu et al., 2003) continue to be unresolved issues in cardiac surgery and therefore better means for myocardial protection are needed.

Levosimendan is a novel calcium sensitizer, which is used to improve myocardial contractility by stabilizing troponin $\mathrm{C}$, and enhancing calcium sensitivity of cardiac myofilaments in heart failure patients (Hasenfuss et al., 1998; Kivikko et al., 2002). Levosimendan has been successfully used in open heart surgery to treat post-operative heart failure and a recent randomized clinical trial showed, that peri-operative levosimendan infusion facilitates weaning from cardiopulmonary bypass at coronary bypass surgery in patients with impaired left ventricular (LV) function (Eriksson et al., 2009). Systemic hypotension may limit the intravenous use of levosimendan and therefore, intracoronary administration has been proposed as an alternative strategy to provide optimal distribution in the heart (Grossini et al., 2005, 2010; Caimmi et al., 2006).

Several in vitro and in vivo studies including models of acute coronary ischemia and cardiac dysfunction show, that levosimendan provides myocardial protection by inducing preconditioning of the myocardium against peri-operative ischemia-reperfusion injury and by involving apoptotic pathway (Maytin and Colucci, 2005; Louhelainen et al., 2007; du Toit et al., 2008; Meyer et al., 2008; Grossini et al., 2010). The direct effect of levosimendan on cardiomyocyte apoptosis is believed to act through ATP-sensitive potassium channels in cardiac mitochondria (Kopustinskiene et al., 2004; Maytin and Colucci, 2005). The anti-apoptotic mechanism of levosimendan is postulated to explain its cardioprotective 
effect at least in part (Louhelainen et al., 2007), although, it is not known whether levosimendan has protective effects against cardiomyocyte apoptosis during open heart surgery. The effect of intracoronary delivery of levosimendan during ischemia on myocardial protection has not been studied.

In order to further elucidate the therapeutic effects of levosimendan in ischemia-reperfusion injury, we used a pig model of open heart surgery to find out whether levosimendan is able to reduce cardiomyocyte apoptosis and preserve left ventricle function after cardiopulmonary bypass and cardioplegic cardiac arrest. We also aimed to determine whether timing and mode of administration of levosimendan has impact on the cardioprotection, using intravenous infusion before ischemia and intracoronary infusion at the inception and during ischemia.

\section{MATERIALS AND METHODS EXPERIMENTAL MODEL}

This study was performed using an experimental open heart surgery model of ischemia-reperfusion injury with pigs $(n=24$, mean weight $30 \pm 0.7 \mathrm{~kg}$ ). In brief, after induction of anesthesia with ketamine and diazepam, all animals were intubated by tracheostomy and ventilated with $60 \%$ oxygen. Both external jugular veins and right common carotid artery were cannulated. Anesthesia was maintained with continues infusion of ketamine and pancuronium. The heart was exposed by median sternotomy and the animals were connected to cardiopulmonary bypass by using a two-stage cannula in right atrium and an aortic cannula in the ascending aorta. Animals were kept in normothermia during the experiment. After the aorta was cross-clamped, all animals received $500 \mathrm{ml}$ cold, crystalloid cardioplegia (modified St. Thomas II, $+5^{\circ} \mathrm{C}$ ) administered antegrade to the ascending aorta to achieve cardiac arrest. After $20 \mathrm{~min}$ of ischemia, an additional $500 \mathrm{ml}$ dose of cardioplegia was given. Aortic cross-clamp was removed after $40 \mathrm{~min}$ of ischemia, defibrillation was performed in case of ventricular fibrillation and the animals were weaned from the cardiopulmonary bypass as soon as possible. Animals were sacrificed after $240 \mathrm{~min}$ of reperfusion at the end of experiment with an injection of potassium chloride. All animals received humane care in compliance with the European Convention on Animal Care. The study protocol was reviewed and approved by the Ethical Committee for Animal Experiments of the University of Turku.

\section{INTERVENTIONS}

In this study, the animals were openly randomized in to three groups, Figure 1: (1) L-IV group received levosimendan $(65 \mu \mathrm{g} / \mathrm{kg}$ : $10 \mathrm{~min}$ intravenous infusion $35 \mu \mathrm{g} / \mathrm{kg}+30 \mathrm{~min}$ infusion $1 \mu \mathrm{g} / \mathrm{kg} / \mathrm{min}$ ) $40 \mathrm{~min}$ before cold, cardioplegic ischemia, (2) L-IC group received an equal dose of levosimendan $(65 \mu \mathrm{g} / \mathrm{kg})$ mixed with the cardioplegia solution, (3) Control group did not receive levosimendan during the experiment. In the L-IV group the levosimendan was mixed with $98 \mathrm{ml}$ of $5 \%$ glucose solution. The L-IC group received levosimendan during cardioplegia administration, mixed with $1000 \mathrm{ml}$ of cardioplegia solution, given in two doses: after cross-clamping the aorta $(500 \mathrm{ml})$ and after $20 \mathrm{~min}$ of ischemia $(500 \mathrm{ml})$. Both in the L-IC and in the Control groups the animals received $10 \mathrm{~min}$ intravenous bolus followed by $30 \mathrm{~min}$ infusion of $5 \%$ glucose solution $(45 \mathrm{ml})$ before cross-clamping the aorta. The levosimendan doses were determined according to an earlier pilot study $(n=7)$.

\section{ASSESSMENT OF MYOCARDIAL AND BLOOD LEVOSIMENDAN CONCENTRATION}

The concentrations of levosimendan and its metabolites OR-1855 and OR-1896 (Kivikko et al., 2002) were assessed from the frozen myocardial samples at the end of the experiment, and from the frozen plasma samples taken 110, 170, 260, and $320 \mathrm{~min}$ after starting the levosimendan by a validated liquid chromatography tandem mass spectrometric method. Levosimendan, OR-1855 and OR-1896 were extracted from plasma or heart homogenate with a mixture of ethyl acetate and hexane. The organic layer was separated and the solvent was evaporated into dryness. The residue was dissolved into the mobile phase. The analytes were isolated with isocratic elution in an Atlantis ${ }^{\mathrm{TM}} \mathrm{dC} 18,2.1 \mathrm{~mm} \times 100 \mathrm{~mm}$ $(5 \mu \mathrm{m})$ column followed by an electrospray ionization with a TurboIonSpray interface and detected using the selected reaction monitoring.

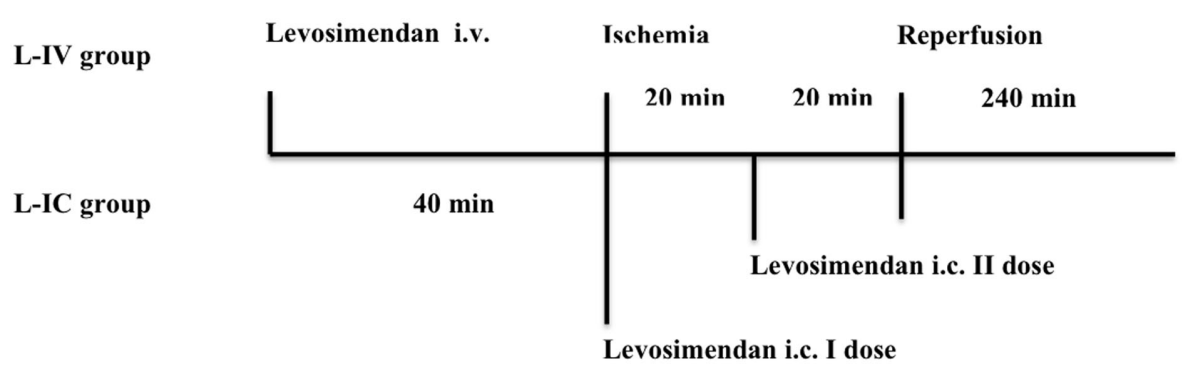

FIGURE 1 | The timing of the levosimendan doses during the experiment. L-IV group = levosimendan $(65 \mu \mathrm{g} / \mathrm{kg})$ given intravenously before ischemia, L-IC group $=$ levosimendan $(65 \mu \mathrm{g} / \mathrm{kg})$ given intracoronary during ischemia in two doses (I and II). During ischemia, all animal were connected to the cardiopulmonary bypass and ischemia was induced using aortic cross-clamp and cold, crystalloid cardioplegia. The reperfusion period was 240 min. i.v., Intravenous, i.c., intracoronary. 


\section{DETECTION OF CARDIOMYOCYTE APOPTOSIS}

Transmyocardial samples were obtained from the left ventricle in order to detect cardiomyocyte apoptosis. Samples were taken before ischemia with a needle (Tru-Cut ${ }^{\circledR}$, Cardinal Health, McGaw Park, IL 60085, USA) and after ischemia-reperfusion period at the end of the experiment by removing the heart. Samples were fixed in neutral buffered formalin over night, embedded in paraffin, and cut at $4 \mu \mathrm{m}$ sections for analysis of apoptosis. Cardiomyocyte apoptosis was detected using terminal transferase mediated dUTP nick end labeling (TUNEL) assay and immunohistochemistry of cleaved caspase-3 as previously described (Vahasilta et al., 2005; Malmberg et al., 2006).

\section{ECHOCARDIOGRAPHY AND HEMODYNAMIC MONITORING}

Echocardiography was performed epicardially to all animals at the beginning of the experiment after median sternotomy before manipulating the heart and was repeated at the end of the experiment. The animals were studied in supine position. Measurements were performed using Acuson Sequoia C512 (Acuson Inc., Mountain View, CA, USA) instrument with $4 \mathrm{~V} 1 \mathrm{c} 4 \mathrm{MHz}$ and 15L8 transducers and recorded in digital mode. Results are the averages of three measurements. Longitudinal contraction of the left ventricle was measured as displacement of the lateral annulus in M-mode using a transducer position equivalent to transthoracic apical four-chamber view. Also left ventricle ejection fraction, early (E) and atrial (A) mitral inflow velocities were recorded. Coronary flow was calculated by multiplying heart rate with velocity time integral from the mid left anterior descending artery. Our group has earlier validated transthoracic echocardiography for measuring coronary flow (Kiviniemi et al., 2007) and in this study the method was further applied using epicardial data acquisition to allow us to detect even small changes in coronary flow. Moreover, our recent paper showed that coronary echocardiography can be used to predict viability after acute infarction (Saraste et al., 2007).

Cardiac out-put, pulmonary capillary wedge pressure and central venous pressure were monitored through the experiment by placing a pediatric thermodilution catheter (SwanGanz ${ }^{\circledR}$, Edwards Lifesciences LLC, Irvine, CA, USA) into the pulmonary artery from the right external jugular vein. Also electrocardiography, heart rate and mean arterial pressure were monitored.

\section{STATISTICAL ANALYSIS}

Power analysis indicated eight animals per group based on the observed variability in apoptosis ( $0.014 \%$ after injury) and longitudinal contraction $(0.10 \mathrm{~mm})$ in our preliminary work. Calculation was based on following details and assumptions (power of 0.8 , two-sided test, alpha 0.05 , differences of $50 \%$ in apoptosis and $20 \%$ in longitudinal contraction between the groups). In order to determine whether the data was normally distributed, the Shapiro-Wilk test was applied. Normally distributed, continuous variables are expressed as mean $\pm \mathrm{SD}$. Non-parametric variables are expresses as median and interquartile range (IQR). The differences between the groups were tested with one-way ANOVA with Tukey HSD post hoc-tests or Kruskal-Wallis-test, and the latter tests were continued with Mann-Whitney $U$ test when needed. The differences within a group were tested with Two-tailed paired
$T$-test or Mann-Whitney $U$ test. Differences were considered significant if the $p$-value was $<0.05$. All analyses were performed using SPSS software package (Version 16.0; SPSS, Inc., Chicago, IL, USA).

\section{RESULTS}

All animals survived the study protocol. The intravenous infusion as well as intracoronary administration of levosimendan was well tolerated. There were no significant hypotension or other hemodynamic problems.

\section{CARDIOMYOCYTE APOPTOSIS}

In the beginning of the experiment, before (pre) the ischemiareperfusion, there were only few apoptotic cardiomyocytes and no significant differences between the groups. Intense positive TUNEL staining in the nucleus and positive immunostaining for active caspase-3 in the nucleus and in the cytoplasm were seen in the tissue samples taken after (post) the ischemiareperfusion period, Figure 2. Apoptosis induction was confirmed by TUNEL assay in all three (pre L-IV $0.002 \pm 0.004 \%$ vs. post L-IV $0.020 \pm 0.017 \% p=0.02$, pre L-IC $0.001 \pm 0.004 \%$ vs. post L-IC $0.02 \pm 0.017 \% p<0.001$, pre control $0.007 \pm 0.013 \%$ vs. post control $0.062 \pm 0.044 \% p=0.01$ ), Figure 3. At the end of the experiment, there were three times more apoptotic cardiomyocytes in the control group when compared with the L-IV group $(p=0.03)$ and L-IC group $(p=0.03)$, but the amounts of apoptosis were comparable in the groups that received levosimendan $(p=1.00)$.

\section{ECHOCARDIOGRAPHY}

Detailed echocardiography data is presented in Table 1. Systolic LV function as assessed by the longitudinal motion of the lateral mitral valve annulus, was comparable in all groups before ischemia (adjusted $p=0.77$ ). However, longitudinal systolic motion of the lateral mitral annulus was significantly reduced in the L-IC and the control groups when compared to the L-IV group (L-IV vs. L-IC $p=0.003$, L-IV vs. control $p=0.01$ ). The difference between the L-IC and control groups was not significant $(p=0.97)$. Consistent

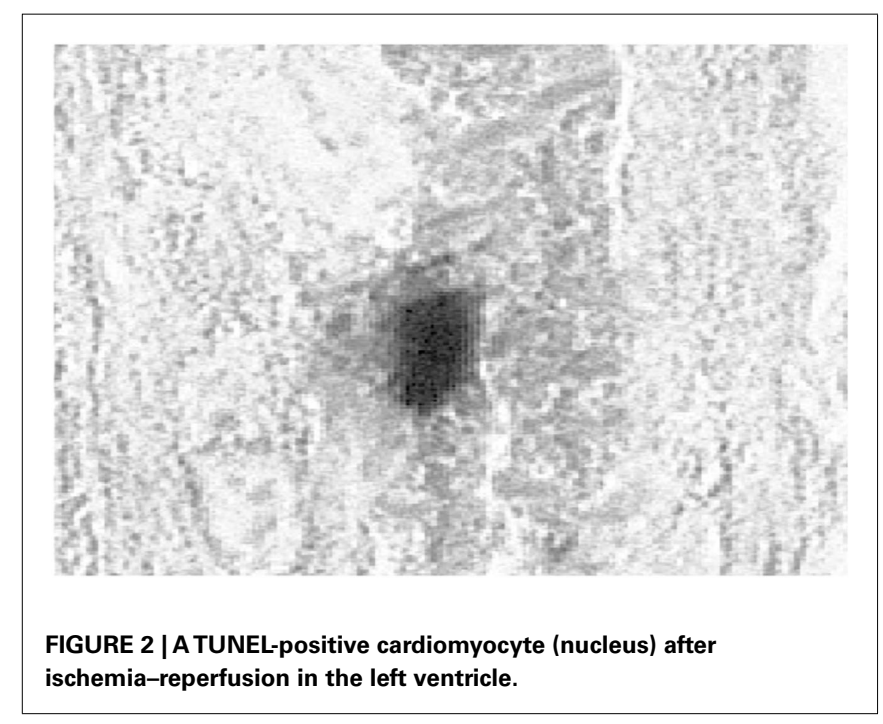




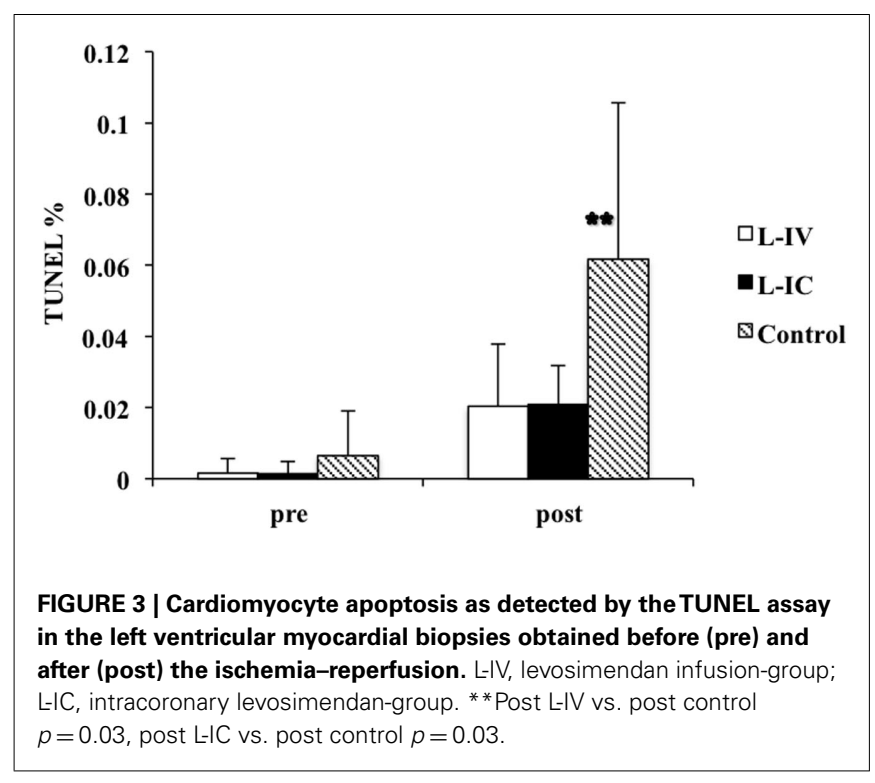

with these findings, ejection fraction was significantly reduced at the end of the experiment in the L-IC $(p=0.04)$ and the control $(p=0.02)$ groups, but not in the L-IV $(p=0.07)$ group as compared with pre-ischemic values. However, no significant differences were detected in ejection fraction between the groups at the end of the experiment.

The coronary flow was comparable in L-IV, L-IC, and control groups at the beginning of the experiment. However, after the ischemia-reperfusion injury, there was a tendency toward higher coronary flow in both levosimendan treatment groups compared to the control group (L-IV $9.33 \pm 3.55 \mathrm{~m} / \mathrm{s}$ vs. control $7.03 \pm 2.43 \mathrm{~m} / \mathrm{s} p=0.40, \mathrm{~L}-\mathrm{IC} \quad 8.77 \pm 3.83 \mathrm{~m} / \mathrm{s}$ vs. control $p=0.58)$.

Early diastolic left ventricle filling velocity, i.e., mitral inflow $E$-wave velocity, was significantly reduced after the ischemiareperfusion injury in all three groups. At the beginning of the experiment, there were no differences between the groups (adjusted $p=0.56)$. At the end of the experiment, there were no significant differences between control and L-IV $(p=0.85)$ or between control and L-IC $(p=0.06)$ groups, but we found a significant difference between L-IV and L-IC groups $(p=0.01)$. In the other echocardiography variables no significant differences between were detected in phase of the study.

\section{HEMODYNAMIC MEASUREMENTS}

Detailed hemodynamic data is presented in Table 2. Compared with preoperative values, cardiac out-put was significantly decreased in all groups at the end of the experiment. At this time, cardiac out-put was significantly lower in L-IC group compared to control group $(p=0.04)$, but it was comparable between L-IV and L-IC groups $(p=0.08)$ as well as L-IV and control groups $(p=0.87)$. There was already at the beginning of the experiment a significant difference between the L-IV and control groups $(p=0.04)$, but not between the L-IV and L-IC $(p=0.09)$ or between the L-IC and control groups $(p=0.81)$. Thus, the absolute
Table 1 | Echocardiography data at the beginning (pre) and at the end of the experiment (post).

\begin{tabular}{|c|c|c|c|}
\hline & L-IV & L-IC & Control \\
\hline \multicolumn{4}{|l|}{$E(\mathrm{~m} / \mathrm{s})$} \\
\hline Pre & $0.67 \pm 0.09$ & $0.63 \pm 0.12$ & $0.71 \pm 0.1$ \\
\hline Post & $0.46 \pm 0.07^{*}$ & $0.35 \pm 0.06^{*}$ & $0.44 \pm 0.04^{*}$ \\
\hline \multicolumn{4}{|l|}{$A(m / s)$} \\
\hline Pre & $0.67 \pm 0.14$ & $0.57 \pm 0.12$ & $0.71 \pm 0.19$ \\
\hline Post & $0.61 \pm 0.15$ & $0.48 \pm 0.11$ & $0.49 \pm 0.1^{*}$ \\
\hline \multicolumn{4}{|l|}{$E / A$} \\
\hline Pre & $1.05 \pm 0.29$ & $1.11[0.11]$ & $1.03 \pm 0.08$ \\
\hline Post & $0.72[0.28]$ & $0.78 \pm 0.22^{*}$ & $0.93 \pm 0.17$ \\
\hline \multicolumn{4}{|l|}{$E^{\prime} / A^{\prime}$} \\
\hline Pre & $0.97 \pm 0.37$ & $0.79 \pm 0.97$ & $1.08 \pm 0.3$ \\
\hline Post & $0.76 \pm 0.17$ & $0.81 \pm 0.35$ & $0.92 \pm 0.29$ \\
\hline \multicolumn{4}{|l|}{ EF (\%) } \\
\hline Pre & $71.07 \pm 2.89$ & $69.12 \pm 6.37$ & $68.13 \pm 6.64$ \\
\hline Post & $62.62 \pm 10.9$ & $59.42 \pm 4.52^{*}$ & $60.07 \pm 4.47^{*}$ \\
\hline \multicolumn{4}{|c|}{ Longit lat (mm) } \\
\hline Pre & $0.76 \pm 0.20$ & $0.78 \pm 0.13$ & $0.82 \pm 0.14$ \\
\hline Post & $0.75 \pm 0.12$ & $0.53 \pm 0.11^{*}$ & $0.54 \pm 0.11 *$ \\
\hline \multicolumn{4}{|c|}{ Coronary flow (m/s) } \\
\hline Pre & $9.06 \pm 5.32$ & $7.32 \pm 1.52$ & $5.1[1.69]$ \\
\hline Post & $9.33 \pm 3.55$ & $8.78 \pm 3.84$ & $7.03 \pm 2.43$ \\
\hline \multicolumn{4}{|c|}{$\operatorname{MDV}(\mathrm{m} / \mathrm{s})$} \\
\hline Pre & $0.25[0.09]$ & $0.25 \pm 0.05$ & $0.21 \pm 0.06$ \\
\hline Post & $0.28 \pm 0.08$ & $0.26 \pm 0.11$ & $0.23 \pm 0.06$ \\
\hline
\end{tabular}

Data presented as mean \pm SE of mean or median and (interquartile range). LIV, levosimendan infusion-group; LIC, intracoronary levosimendan-group. E, early; $A$, late mitral inflow velocity; $E^{\prime} / A^{\prime}$, velocity ratio on the mitral annulus; $E F$, ejection fraction; Longit lat, longitudinal systolic motion of the lateral mitral annulus; $M D V$, mean diastolic coronary flow. ${ }^{*} p<0.05$ pre vs. post.

decrease between pre-and post-ischemic cardiac out-put was significantly lower in L-IV than control group $(p=0.03)$, whereas it was comparable between L-IV and L-IC $(p=0.93)$ as well as L-IC and control groups $(p=0.06)$. Mean arterial pressure was significantly higher at the end of the experiment only in the L-IV group when compared to the values measured at the beginning of the experiment (pre vs. post $p=0.01$ ). Calculated systemic vascular resistance $[\mathrm{SVR}=$ (mean arterial pressure - central venous pressure)/cardiac out-put] was significantly increased in all three groups during the experiment, but there were no significant differences between the groups. The absolute increase in SVR (post-pre) was significantly higher in L-IC than control group $(p=0.04)$, whereas it was comparable between L-IV and control $(p=0.18)$ as well as L-IV and L-IC groups $(p=0.74)$. There were no other significant differences between the groups or between pre- and post-experimental values.

\section{CONCENTRATIONS OF LEVOSIMENDAN, OR-1855 AND OR-1896}

We detected effective doses of either levosimendan or its active metabolite OR-1896 in the myocardium or plasma samples after both intracoronary and intravenous administration. The levosimendan concentration was significantly higher in the L-IC group 
Table 2 | Results of the hemodynamic measurements at the beginning (pre) and at the end of the experiment (post).

\begin{tabular}{|c|c|c|c|}
\hline & L-IV & L-IC & Control \\
\hline \multicolumn{4}{|c|}{$\mathrm{CO}(1 / \mathrm{min})$} \\
\hline Pre & $4.07 \pm 0.70$ & $3.38 \pm 0.37$ & $3.23 \pm 0.37$ \\
\hline Post & $2.28 \pm 0.61^{*}$ & $1.57 \pm 0.23^{*}$ & $2.00 \pm 0.35^{*}$ \\
\hline \multicolumn{4}{|c|}{$\mathrm{MAP}(\mathrm{mmHg})$} \\
\hline Pre & $61.88 \pm 8.71$ & $65.88 \pm 14.5$ & $61.00 \pm 8.11$ \\
\hline Post & $83.5 \pm 17.71^{*}$ & $85.38 \pm 21.82$ & $80.25 \pm 17.90$ \\
\hline \multicolumn{4}{|c|}{$\mathrm{HR}(/ \mathrm{min})$} \\
\hline Pre & $105.13 \pm 16.39$ & $111 \pm 9.99$ & $106.13 \pm 20.1$ \\
\hline Post & $105.5 \pm 23.13$ & $108.63 \pm 12.97$ & $105.86 \pm 12.9$ \\
\hline \multicolumn{4}{|c|}{ CVP (mmHg) } \\
\hline Pre & $3.63 \pm 3.70$ & $3.13 \pm 0.99$ & $2.88 \pm 0.83$ \\
\hline Post & $3.13 \pm 3.04$ & $4.25 \pm 2.05$ & $4.38 \pm 1.30$ \\
\hline \multicolumn{4}{|c|}{ PCWP (mmHg) } \\
\hline Pre & $3.75 \pm 3.77$ & $4.25 \pm 1.67$ & $4.38 \pm 2.2$ \\
\hline Post & $3.13 \pm 3.18$ & $5.5 \pm 4.44$ & $3.75 \pm 1.16$ \\
\hline \multicolumn{4}{|l|}{ SVR } \\
\hline Pre & $14.51 \pm 1.48$ & $18.67 \pm 4.11$ & $18.28 \pm 3.88$ \\
\hline Post & $38.63 \pm 9.90^{*}$ & $51.42 \pm 9.38^{*}$ & $38.95 \pm 11.2^{*}$ \\
\hline \multicolumn{4}{|c|}{ Calculated SW } \\
\hline Pre & $2.49 \pm 0.92$ & $2.02 \pm 0.59$ & $1.93 \pm 0.52$ \\
\hline Post & $1.86 \pm 0.93$ & $1.25 \pm 0.43$ & $1.54 \pm 0.49$ \\
\hline
\end{tabular}

Data presented as mean \pm SEM. L-IV, levosimendan infusion-group, L-IC, intracoronary levosimendan-group. CO, cardiac out-put; MAP, mean arterial pressure; $H R$, heart rate; CVP, central venous pressure; PCWP, pulmonary capillary wedge pressure; $S V R$, systemic vascular resistance, Calculated $S W=$ left ventricle stroke work $=(C O / H R) \times M A P .{ }^{*} p<0.05$ pre vs. post, $p<0.05$ between groups (values in bold).

than in the L-IV group in the myocardial biopsies taken at the end of the experiment, Figure 4. In the myocardial samples no traces of metabolites OR-1855 or OR-1896 were found. In the plasma samples taken during the experiment, metabolite OR-1896, but no traces of levosimendan or metabolite OR-1855 was detected, Figure 5. The concentrations of OR-1896 were significantly higher in the L-IC group than in the L-IV group $170 \min (p=0.001)$ and $260 \mathrm{~min}(p=0.004)$ after levosimendan. At $110 \mathrm{~min}(p=0.08)$ and $320 \mathrm{~min}(p=0.28)$ there were no significant differences.

\section{DISCUSSION}

The main result of this study with an in vivo pig model of open heart surgery is that levosimendan administered intracoronary during ischemia provides cardioprotective effect, demonstrated by reduced myocardial apoptosis at acute phase of ischemiareperfusion injury after cardiopulmonary bypass and cardioplegic cardiac arrest. Although both administration modes of levosimendan prevented similarly apoptosis, preoperatively started intravenous administration was superior to intracoronary started at the time of ischemia-reperfusion, assessed by echocardiographyderived systolic cardiac function. This suggests that intravenous preoperative administration may be more effective in preventing the post-operative myocardial stunning, as compared to intracoronary administration at the beginning and during ischemia.
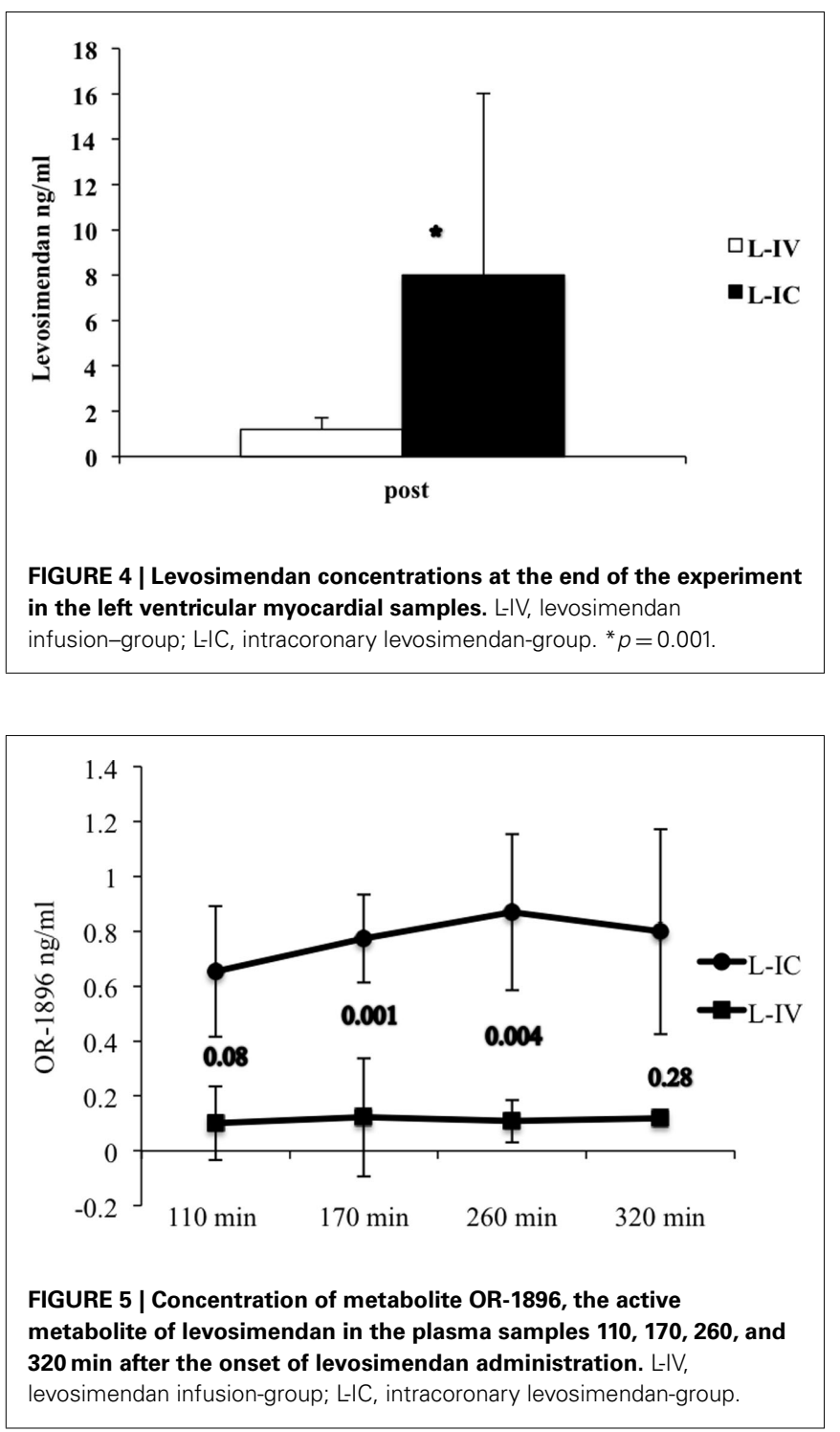

Levosimendan protects cardiomyocytes from apoptosis in experimental models of cardiac pressure overload (Louhelainen et al., 2007) and heart failure induced by viral myocarditis (Latva-Hirvela et al., 2009). Moreover, levosimendan induces preconditioning and decreases myocardial infarct size in an isolated perfused rat heart model of acute ischemia-reperfusion injury (Ozturk et al., 2010). This is the first study to evaluate the effects of levosimendan on cardiomyocyte apoptosis in an in vivo experimental model of global, cardioplegic, myocardial ischemia that closely resembles human cardiac surgery. This study is also the first to compare peri-ischemic intracoronary administered levosimendan to pre-ischemic intravenous levosimendan infusion.

Thus, this study reveals a novel finding that levosimendan prevents cardiomyocyte apoptosis after global ischemia-reperfusion injury in vivo and that this anti-apoptotic effect is conferred by both pre-ischemic intravenous administration and peri-ischemic intracoronary administration. Intracoronary levosimendan has 
been successfully used after global or regional ischemia in previous studies in order to prevent post-ischemic myocardial dysfunction and cardiomyocyte apoptosis (Jamali et al., 1997; Grossini et al., 2005, 2010; Caimmi et al., 2006). Our results confirm that levosimendan prevents ischemia-reperfusion induced apoptosis. Moreover, it is a novel finding that levosimendan given before cold, global ischemia as an infusion, reduces cardiomyocyte apoptosis equally to levosimendan given during ischemia when the doses are comparable.

Levosimendan has been shown to prevent myocardial stunning and heart failure after cardiac surgery (Eriksson et al., 2009; Landoni et al., 2010). Our results indicate, that levosimendan administered with cardioplegia in the beginning and during global ischemia, is not as effective as pre-ischemic intravenous infusion in preserving systolic and diastolic LV function after $40 \mathrm{~min}$ of ischemia and 240 min of reperfusion, although levosimendan concentration was higher in myocardial samples and there were no traces of metabolites. This result might be explained by the fact that pre-ischemic levosimendan has more time to effect on cardiomyocytes and might have better access into the myocardium when the infusion is normothermic, although the differences in the plasma concentrations indicate exceptionally fast metabolism of levosimendan and its metabolites OR-1855 and OR-1896 in pig. On the other hand, fast metabolism does not explain why there was only levosimendan and no metabolites to be found in the myocardial samples. However, the equal amounts of apoptotic cardiomyocytes after both intracoronary and intravenous levosimendan administration support the idea of comparable direct effects on the level of myocardium. With longer reperfusion period there might be a greater difference in myocardial apoptosis between the treatment groups. The beneficial action of intravenous levosimendan might be partly mediated by systemic effects, whereas intracoronary administration might be limited to local cardiac effects. Higher intracellular levosimendan concentration supports our hypothesis of increasing the concentration of levosimendan in the myocardium without systemic hypotension. The levosimendan doses used in this study were higher than in normal clinical practise (Eriksson et al., 2009). However, the OR-1896 plasma concentrations found in this study closely resembles concentrations of human studies (Lehtonen and Pöder, 2007), and it has been shown before, that higher doses of levosimendan are needed with pig model to see possible hemodynamic changes (Busk et al., 2006).

The favorable effects of levosimendan on systemic hemodynamics include marked reduction of afterload caused by

\section{REFERENCES}

Busk, M., Maeng, M., Kristensen, J., Berg, J. S., Mortensen, U. M., Nielsen, T. T., and Nilelsen-Kudsk, J. E. (2006). Effects of levosimendan on myocardial infarct size and hemodynamics in a closedchest porcine ischemia-reperfusion model. Cardiovasc. Drugs Ther. 20, 335-342.

Caimmi, P. P., Grossini, E., Molinari, C., Vacca, G., and Teodori, G. (2006). Intracoronary infusion of levosimendan to treat postpericardiotomy heart failure. Ann. Thorac. Surg. 82, e33-e34.

du Toit, E. F., Genis, A., Opie, L. H., Pollesello, P., and Lochner, A. (2008). A role for the RISK pathway and $\mathrm{K}$ (ATP) channels in pre- and postconditioning induced by levosimendan in the isolated guinea pig heart. Br. J. Pharmacol. 154, 41-50.

Eriksson, H. I., Jalonen, J. R., Heikkinen, L. O., Kivikko, M. O., Laine, M., Leino, K. A., Kuitunen, A. H., Kuttila, K. T., Peräkylä, T. K., Sarapohja, T., Suojaranta-Ylinen, R. T., Valtonen,

vasodilatation (Kivikko et al., 2002). Consistent with this explanation, cardiac out-put was higher in the L-IV than L-IC group after ischemia-reperfusion. These findings also suggest that at least after short reperfusion period, cardiomyocyte apoptosis does not have direct effect on post-operative myocardial stunning. In contrast to the expected hypotension, mean arterial pressure was actually higher in animals with levosimendan treatment than without.

In conclusion, intracoronary levosimendan during ischemia prevents cardiomyocytes from apoptosis in experimental animal pig model of ischemia-reperfusion injury with cardiopulmonary bypass and cardioplegic cardiac arrest. Intracoronary administration of levosimendan at the onset and during ischemia reduces apoptosis equally as pre-ischemic intravenous levosimendan infusion, when the doses are comparable. However, pre-ischemic intravenous infusion is associated with better preservation of LV systolic and diastolic function when compared with peri-ischemic intracoronary administration. With intracoronary administered levosimendan there were higher concentrations of levosimendan in the left ventricle muscle biopsies and active metabolite OR-1896 in the plasma samples.

\section{LIMITATIONS}

We recognize the limitations of simulating human cardiac surgery induced ischemia-reperfusion injury using an animal model with healthy young pigs. However, this animal model is reproducible and well-established (Vahasilta et al., 2005; Malmberg et al., 2006). To minimize the loss of animals during the experiment, the followup time was limited to $240 \mathrm{~min}$ to allow successful completion. Our results can not be directly applied to clinical setting and whether the detected acute positive effects will translate to better cardiac function and even lower mortality at long-term, remains to be studied.

\section{ACKNOWLEDGMENTS}

There are conflict of interest. We thank Jouko Levijoki MSc (Pharm.) from Orion Pharma, and also Jan Kiss $\mathrm{MD}, \mathrm{PhD}$ and Jarmo Gunn MD for assistance in this study. This study was supported by the Aarno Koskelo foundation and by the Clinical Research funding (EVO) of Turku University Hospital. Orion Pharma (Espoo, Finland) supported this study by providing the levosimendan (Simdax ${ }^{\circledR}$, Orion Pharma, Espoo, Finland) and measuring the levosimendan, OR-1855 and OR-1896 concentrations.

M., and Salmenperä, M. T. (2009). Levosimendan facilitates weaning from cardiopulmonary bypass in patients undergoing coronary artery bypass grafting with impaired left ventricular function. Ann. Thorac. Surg. 87, 448-454.

Gottlieb, R. A., Burleson, K. O., Kloner, R. A., Babior, B. M., and Engler, R. L. (1994). Reperfusion injury induces apoptosis in rabbit cardiomyocytes. J. Clin. Invest. 94, 1621-1628.

Grossini, E., Caimmi, P. P., Molinari, C., Teodori, G., and Vacca,
G. (2005). Hemodynamic effect of intracoronary administration of levosimendan in the anesthetized pig. J. Cardiovasc. Pharmacol. 46, 333-342.

Grossini, E., Caimmi, P. P., Platini, F., Molnari, C., Uberti, F., Cattaneo, M., Vaenta, G., Mary, D. A., Vagga, G., and Tessitore, L. (2010). Modulation of programmed forms of cell death by intracoronary levosimendan during regional myocardial ischemia in anesthetized pigs. Cardiovasc. Drugs Ther. 24, 5-15. 
Hasenfuss, G., Pieske, B., Castell, M., Kretschmann, B., Maier, L. S., and Just, H. (1998). Influence of the novel inotropic agent levosimendan on isometric tension and calcium cycling in failing human myocardium. Circulation 98 , 2141-2147.

Jamali, I. N., Kersten, J. R., Pagel, P. S., Hettrick, D. A., and Warltier, D. C. (1997). Intracoronary levosimendan enhances contractile function of stunned myocardium. Anesth. Analg. 85, 23-29.

Kivikko, M., Antila, S., Eha, J., Lehtonen, L., and Pentikainen, P. J. (2002). Pharmacodynamics and safety of a new calcium sensitizer, levosimendan, and its metabolites during an extended infusion in patients with severe heart failure. J. Clin. Pharmacol. 42, 43-51.

Kiviniemi, T. O., Toikka, J. O., Koskenvuo, J. W., Saraste, A., Saraste, M., Parkka, J. P., Raitakari, O. T., and Hartiala, J. J. (2007). Vasodilation of epicardial coronary artery can be measured with transthoracic echocardiography. Ultrasound Med. Biol. 33, 362-370.

Kopustinskiene, D. M., Pollesello, P., and Saris, N. E. (2004). Potassiumspecific effects of levosimendan on heart mitochondria. Biochem. Pharmacol. 68, 807-812.
Landoni, G., Mizzi, A., Biondi-Zoccai, G., Bruno, G., Bignami, E., Corno, L., Zambon, M., Gerli, C., and Zangrillo, A. (2010). Levosimendan reduces mortality in critically ill patients. A meta-analysis of randomized controlled studies. Minerva Anestesiol. 76, 276-286.

Latva-Hirvela, J., Kyto, V., Saraste, A., Vuorinen, T., Levijoki, J., and Saukko, P. (2009). Effects of levosimendan in experimental acute coxsackievirus myocarditis. Eur. J. Clin. Invest. 39, 876-882.

Lehtonen, L., and Pöder, P. (2007). The utility of levosimendan in the treatment of heart failure. Ann. Med. 39, 2-17.

Louhelainen, M., Vahtola, E., Kaheinen, P., Leskinen, H., Merasto, S., Kytö, V., Finckenberg, P., Colucci, W. S., Levijoki, J., Pollosello, P., Haikala, H., and Mervaala, E. M. A. (2007). Effects of levosimendan on cardiac remodeling and cardiomyocyte apoptosis in hypertensive Dahl/Rapp rats. $B r$. J. Pharmacol. 150, 851-861.

Malmberg, M., Vahasilta, T., Saraste, A., Kytö, V., Kentala, E., Kallajoki, M., and Savunen, T. (2006). Cardiomyocyte apoptosis and duration of aortic clamping in pig model of open heart surgery. Eur. J. Cardiothorac. Surg. 30, 480-484.
Maytin, M., and Colucci, W. S. (2005). Cardioprotection: a new paradigm in the management of acute heart failure syndromes. Am. J. Cardiol. 96 , 26G-31G.

Meyer, K., Schipke, J. D., Klocke, R. C., Gams, E., and Korbmacher, B. (2008). Inotropic, vasodilating and preconditioning actions of levosimendan in the heart. Thorac. Cardiovasc. Surg. 56, 379-385.

Ozturk, T., Gok, S., and Nese, N. (2010). Levosimendan attenuates reperfusion injury in an isolated perfused rat heart model. J. Cardiothorac. Vasc. Anesth. 24, 624-628.

Saraste, A., Koskenvuo, J. W., Saraste, M., Parkka, J., Toikka, J., Naum, A. Ukkonen, H., Knuuti, J., Airaksinen, J., and Hartiala, J. (2007). Coronary artery flow velocity profile measured by transthoracic Doppler echocardiography predicts myocardial viability after acute myocardial infarction. Heart 93, 456-457.

Vahasilta, T., Saraste, A., Kyto, V., Malmberg, M., Kiss, J., Kentala, E., Kallajoki, M., and Savunen, T. (2005). Cardiomyocyte apoptosis after antegrade and retrograde cardioplegia. Ann. Thorac. Surg. 80, 2229-2234.

Wu, Z. K., Laurikka, J., Saraste, A., Kytö, V., Pehkonen, E. J., Savunen, T., and Tarkka, M. R. (2003). Cardiomyocyte apoptosis and ischemic preconditioning in open heart operations. Ann. Thorac. Surg. 76, 528-534.

Conflict of Interest Statement: The authors declare that the research was conducted in the absence of any commercial or financial relationships that could be construed as a potential conflict of interest.

Received: 22 November 2011; accepted: 25 January 2012; published online: 14 February 2012.

Citation: Malmberg M, Vähäsilta T, Saraste A, Koskenvuo JW, Pärkkä $J P$, Leino $K$, Laitio $T$, Stark $C$ Heikkilä A, Saukko $P$ and Savunen $T$ (2012) Intracoronary levosimendan during ischemia prevents myocardial apoptosis. Front. Physio. 3:17. doi: 10.3389/fphys.2012.00017

This article was submitted to Frontiers in Clinical and Translational Physiology, a specialty of Frontiers in Physiology.

Copyright (๑) 2012 Malmberg, Vähäsilta Saraste, Koskenvuo, Pärkkä, Leino, Laitio, Stark, Heikkilä, Saukko and Savunen. This is an open-access article distributed under the terms of the Creative Commons Attribution Non Commercial License, which permits noncommercial use, distribution, and reproduction in other forums, provided the original authors and source are credited. 